\title{
ANALISIS KETAHANAN ABRASI MATERIAL OUTSOLE POLYURETHANE (PU) \& NITRILE BUTADINE RUBBER (NBR) PADA SAFETY SHOES CHEETAH DI PT. X
}

\author{
Suherna ${ }^{1, *}$, Patunru P. ${ }^{2}$, Maspah $^{3}$ \\ 1,2,3 Teknik Mesin, Fakultas Teknologi Industri, Universitas Balikpapan, \\ Jl.Pupuk Raya, 76114, Kalimantan Timur, Indonesia \\ *E-mail: suherna@uniba-bpn.ac.id
}

\begin{abstract}
ABSTRAK
Peningkatan mutu, kekuatan dan life time ditinjau dari ketahanan abrasi pada material outsole safety shoes Cheetah dimana dalam proses penggunaannya beberapa material mengalami penurunan kualitas, disamping karena faktor pemakaian, faktor perawatan, dan beberapa material tersebut juga mengalami masalah pada saat penggunaan . Penelitian ini untuk mengetahui ketahanan abrasi pada masing - masing material Outsole Polyurethane (PU) dan Nitrile Butadine Rubber (NBR). Uji ketahanan abrasi pada material tersebut, metode dengan menggunakan alat DIN Abrasion tester. Pengambilan data pada material outsole dilakukan pada material outsole dengan kondisi baru dan yang sudah digunakan di lapangan selama masa 1 tahun dengan metode mengukur indeks ketahanan abrasi dan massa jenis material.Perhitungan rata - rata ketahanan abrasi untuk type Polyurethane (PU) yang bersifat baru adalah $37,11 \mathrm{~mm}^{3} /$ tahun, sedangkan rata-rata ketahanan abrasi untuk type Polyurethane (PU) yang sudah digunakan dalam masa 1 tahun adalah $33,19 \mathrm{~mm}^{3} /$ tahun sehingga mengalami selisih 3,92 $\mathrm{mm}^{3} /$ tahun atau sekitar $11 \%$ penurunan kualitas ketahanan abrasi. Rata - rata ketahanan abrasi dengan type Nitrile Butadine Rubber (NBR) yang bersifat baru adalah 108,26 mm/tahun, rata-rata ketahanan abrasi untuk type Nitrile Butadine Rubber (NBR) dengan kondisi sudah digunakan dalam masa 1 tahun adalah $107,44 \mathrm{~mm}^{3} /$ tahun sehingga mengalami selisih $0,82 \mathrm{~mm}^{3} /$ tahun atau sekitar $1 \%$ penurunan kualitas untuk ketahanan abrasi. Batas toleransi abrasi yang sudah diatur sesuai SOP (Standart Operational Procedure) terhadap ketahanan abrasi jika SG $\geq 0.9$ Maka Abrasive Max 150 dan jika SG $\leq 0.9$ Maka Abrasive Max 250.
\end{abstract}

Kata kunci : sepatu safety, karet, poliuretan, nitril

\section{ABSTRACT}

Improved quality, strength and life time in terms of abrasion resistance on safety shoes outsole Cheetah material where the process use of some material has decreased in quality, besides due to usage factors, maintenance factors, and some of these materials also experience problems during use. This study is done to determine the abrasion resistance of each Outsole Polyurethane (PU) material and Nitrile Butadiene Rubber (NBR). Abrasion resistance test on the material method used the DIN Abrasion tester. Retrieval of data on outsole material was carried out on the outsole material with new conditions and that has been used in the field for a period of 1 year with a method of measuring abrasion resistance index and density of material. Calculation of average abrasion resistance for new Polyurethane (PU) type was $37,11 \mathrm{~mm}^{3} /$ year, while the average abrasion resistance for Polyurethane (PU) type that has been used for 1 year was $33.19 \mathrm{~mm}^{3} /$ year so that the difference is $3.92 \mathrm{~mm}^{3}$ / year or about $11 \%$ quality decrease of abrasion resistance. The average abrasion resistance with the new Nitrile Butadiene Rubber (NBR) type was $108.26 \mathrm{~mm}^{3}$ / year, the average abrasion resistance for Nitrile Butadiene Rubber (NBR) type with conditions already used in 1 year period was $107.44 \mathrm{~mm} 3 /$ year so that the difference is $0.82 \mathrm{~mm}^{3} /$ year or about $1 \%$ decrease in quality decrease of abrasion resistance. Abrasion tolerance limits that 
have been set according to the SOP (Standard Operational Procedure) against abrasion resistance if $S G \geq 0.9$ then the Abrasive Max is 150 and if $S G \leq 0.9$ Then the Abrasive Max is 250.

Keywords: Safety shoes, rubber, polyurethane, Nitrile

\section{PENDAHULUAN}

Untuk memenuhi pertumbuhan industri dan kebutuhan akan keselamatan kerja di Indonesia dan negara lain yang semakin hari terus meningkat, baik untuk kebutuhan industri pertambangan, perminyakan, konstruksi serta perkebunan.

Merek dagang CHEETAH telah membangun reputasi yang solid untuk sepatu keamanan berkualitas dan standar manufaktur tanpa kompromi. Filosofi yang sama telah diperluas ke rangkaian APD ( Alat Pelindung Diri ) untuk memberikan solusi keselamatan yang lengkap untuk berbagai bidang pekerjaan,[1,2].

Dalam proses penggunaannya dilapangan terdapat beberapa Material Outsole yang sudah memasuki penurunan kualitas, disamping perawatan, beberapa Material Outsole tersebut juga mengalami masalah pada saat penggunaan di lapangan yang tidak sesuai dengan Medan / Area yang disarankan, [2,5].

Dengan adanya penelitian ini bertujuan untuk mengetahui ketahanan abrasi pada penggunaan material Polyurethane (PU) dan Nitrile Butadine Rubber (NBR) pada Outsole Cheetah Safety Shoes untuk meningkatkan mutu, kekuatan dan life time ditinjau dari ketahanan abrasi, diharapkan penelitian ini dapat menambah pengetahuan dan pengalaman untuk dijadikan nilai tambah dan dijadikan kompeten dalam dunia kerja,[1,6].

Tujuan Penelitian ini adalah:

- Untuk mengetahui ketahanan abrasi pada material Outsole Polyurethane (PU) dan Nitrile Butadine Rubber (NBR) setelah di aplikasikan di lapangan serta pencegahannya.

- Untuk mengetahui jenis material manakah yang bisa bertahan lebih lama untuk penggunaan di lapangan dari masing masing material Outsole Polyurethane (PU) dan Nitrile Butadine Rubber (NBR) pada safety shoes, $[5,8]$.

\section{METODE PENELITIAN}

Berikut ini beberapa metode atau langkah - langkah yang dilakukan untuk mengumpulkan data-data penelitian:

a. Observasi Perusahaan, ditahap ini dilakukan observasi langsung ke perusahaan untuk mengetahui masalah-masalah apa yang terjadi di lapangan.

b. Identifikasi Permasalahan, dari hasil observasi, selanjutnya ditetapkan perumusan masalah yang terjadi di perusahaan. Mengidentifikasi suatu masalah dapat dilakukan dengan mencari penyebab timbulnya masalah dan kemudian mencari solusi yang tepat untuk memecahkannya.

c. Metode literatur, yaitu menggunakan buku referensi dan jurnal yang berkaitan dengan pembahasan analisis dari material Polyurethane (PU) dan Nitrile Butadine Rubber (NBR) kemudian dilakukanlah studi literatur untuk menunjang penelitian. Teori - teori pendukung harus yang berhubungan dengan perumusan masalah. Teori tersebut berguna untuk menemukan metode pemecahan masalah yang tepat agar penelitian yang dilakukan berjalan secara terarah, $[3,4,6]$.

d. Pengumpulan data, pada penelitian ini datadata yang diperlukan adalah Material dari dua jenis Outsole yakni Polyurethane (PU) $\&$ Nitrile Butadiene Rubber (NBR)

Adapun tahapan penelitian yang dijalankan agar hasil yang diinginkan sesuai dengan yang diharapkan :

a. Menyediakan material yang akan dianalisa untuk menghitung ketahanan abrasi

b. Mengecek material yang akan digunakan dan memastikan material dalam keadaan bersih agar kotoran atau debu tidak menempel. 
c. Mengecek alat dan bahan untuk melakukan pekerjaan agar sesuai dengan peraturan dan SOP ( Standar Operasional Prosedur) Perusahaan.

d. Memotong material dari masing- masing yang akan digunakan untuk menguji ketahanan abrasi menggunakan alat DIN Abrasion tester, lalu menimbang berat awal speciment menggunakan alat Electronic Scale Balance, [1,2].

e. Menghitung berat dan volume untuk menghitung masa jenis menggunakan alat Density Moisture.

Diagram alir penelitian:

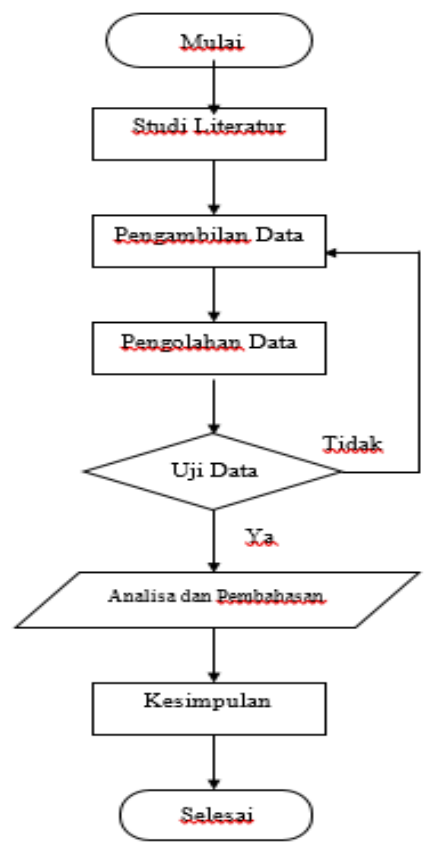

Gambar 1. Diagram alir penelitian

\section{HASIL DAN PEMBAHASAN}

Perhitungan Berat Jenis Pada Outsole PU (baru)

Tabel 1. Hasil Perhitungan Berat Jenis Pada Outsole PU (baru)

\begin{tabular}{l|c|c|c}
\hline Keterangan & Kanan & Kiri & $\begin{array}{c}\text { Rata- } \\
\text { rata }\end{array}$ \\
\hline $\begin{array}{l}\text { Berat Outsole } \\
\text { (gram) }\end{array}$ & 2,37 & 2,37 & 2,37 \\
\hline
\end{tabular}

\begin{tabular}{l|c|c|c}
\hline $\begin{array}{l}\text { Volume } \\
\text { Outsole }\left(\mathrm{cm}^{3}\right)\end{array}$ & 0,38 & 0,38 & 0,38 \\
\hline $\mathrm{SG}\left(\mathrm{g} / \mathrm{cm}^{3}\right)$ & 1,19 & 1,19 & 1,19 \\
\hline
\end{tabular}

Perhitungan Berat Jenis Pada Outsole PU (sudah digunakan) $[5,8]$

$\mathrm{SG}=\mathrm{m} /(\mathrm{m}-\mathrm{v})$

Tabel 2. Hasil Perhitungan Berat Jenis Pada Outsole PU (sudah digunakan)

\begin{tabular}{l|c|c|c}
\hline Keterangan & Kanan & Kiri & $\begin{array}{c}\text { Rata- } \\
\text { rata }\end{array}$ \\
\hline $\begin{array}{l}\text { Berat Outsole } \\
\text { (gram) }\end{array}$ & 2,30 & 2,30 & 2,30 \\
\hline $\begin{array}{l}\text { Volume } \\
\text { Outsole }\left(\mathrm{cm}^{3}\right)\end{array}$ & 0,35 & 0,35 & 0,35 \\
\hline $\mathrm{SG}\left(\mathrm{g} / \mathrm{cm}^{3}\right)$ & 1,18 & 1,18 & 1,18 \\
\hline
\end{tabular}

Berikut ini merupakan data untuk perhitungan berat jenis pada material Outsole Nitrile Butadiene Rubber (NBR) untuk material yang bersifat baru dan yang sudah digunakan selama waktu 1 tahun.

Perhitungan Berat Jenis Pada Outsole NBR (baru), [5,8].

$$
\mathrm{SG}=\mathrm{m} /(\mathrm{m}-\mathrm{v})
$$

Tabel 3. Hasil Perhitungan Berat Jenis Pada Outsole NBR (baru)

\begin{tabular}{l|c|c|c}
\hline Keterangan & Kanan & Kiri & $\begin{array}{c}\text { Rata- } \\
\text { rata }\end{array}$ \\
\hline $\begin{array}{l}\text { Berat } \\
\begin{array}{l}\text { Outsole } \\
\text { (gram) }\end{array}\end{array}$ & 3,45 & 3,45 & 3,45 \\
\hline $\begin{array}{l}\text { Volume } \\
\text { Outsole } \\
\left(\mathrm{cm}^{3}\right)\end{array}$ & 0,50 & 0,50 & 0,50 \\
\hline $\mathrm{SG}\left(\mathrm{g} / \mathrm{cm}^{3}\right)$ & 1,17 & 1,17 & 1,17 \\
\hline
\end{tabular}

Perhitungan Berat Jenis Pada Outsole NBR (sudah digunakan) 
Tabel 4. Hasil Perhitungan Berat Jenis Pada Outsole NBR (sudah digunakan)

\begin{tabular}{l|c|c|c}
\hline Keterangan & Kanan & Kiri & $\begin{array}{c}\text { Rata- } \\
\text { rata }\end{array}$ \\
\hline $\begin{array}{l}\text { Berat } \\
\text { Outsole } \\
\text { (gram) }\end{array}$ & 3,43 & 3,43 & 3,43 \\
\hline $\begin{array}{l}\text { Volume } \\
\text { Outsole } \\
\left(\mathrm{cm}^{3}\right)\end{array}$ & 0,48 & 0,48 & 0,48 \\
\hline $\mathrm{SG}\left(\mathrm{g} / \mathrm{cm}^{3}\right)$ & 1,16 & 1,16 & 1,16 \\
\hline
\end{tabular}

\section{Perhitungan Ketahanan Abrasi}

Data hasil dari penelitian tepatnya akan dilakukan perhitungan Abrasi dengan menggunakan rumus sebagai berikut :

Rumus Abrasi [2][3]

$\left(\mathrm{m}_{1}-\mathrm{m}_{2}\right) \times 200 /(\mathrm{SG} \times 0,6)$

Perhitungan Abrasi Material Polyurethane (PU) bersifat baru

Tabel 5. Hasil Perhitungan Abrasi material PU

\begin{tabular}{|c|c|c|c|}
\hline \multicolumn{4}{|c|}{ (baru) } \\
\hline Font/depan & A & B & $\begin{array}{l}\text { RATA- } \\
\text { RATA }\end{array}$ \\
\hline $\begin{array}{c}\text { Berat } \\
\text { Speciment } \\
\text { Awal (g) }\end{array}$ & 1,9 & 2,03 & 1,97 \\
\hline $\begin{array}{c}\text { Berat } \\
\text { Speciment } \\
\text { Akhir }(g)\end{array}$ & 1,79 & 1,88 & 1,84 \\
\hline Heel/Belakang & $\mathrm{C}$ & $\mathrm{D}$ & \\
\hline $\begin{array}{c}\text { Berat } \\
\text { Speciment } \\
\text { Awal }(\mathrm{g})\end{array}$ & 1,50 & 1,42 & 1,46 \\
\hline $\begin{array}{c}\text { Berat } \\
\text { Speciment } \\
\text { Akhir }(\mathrm{g})\end{array}$ & 1,35 & 1,30 & 1,33 \\
\hline $\begin{array}{l}\text { Abrasi Front } \\
\left(\mathrm{mm}^{3}\right)\end{array}$ & 30,81 & 42,01 & 36,41 \\
\hline $\begin{array}{l}\text { Abrasi Heel } \\
\left(\mathrm{mm}^{3}\right)\end{array}$ & 42,01 & 33,61 & 37,81 \\
\hline ABRASI RA & -RATA & $\overline{\mathrm{EEL}}$ & 37,11 \\
\hline
\end{tabular}

Keterangan :

*Jika SG $\geq 0,9$ Maka Abrasive Max

150
*Jika SG $\leq 0,9$ Maka Abrasive Max 250

Perhitungan Abrasi Material Polyurethane (PU) dengan kondisi sudah digunakan selama 1 tahun.

Tabel 6. Hasil Perhitungan Abrasi material PU (sudah digunakan)

\begin{tabular}{c|c|c|c}
\hline Font/depan & A & B & $\begin{array}{c}\text { RATA- } \\
\text { RATA }\end{array}$ \\
\hline $\begin{array}{c}\text { Berat } \\
\text { Speciment } \\
\text { Awal (g) }\end{array}$ & 1,88 & 1,94 & 1,91 \\
\hline $\begin{array}{c}\text { Berat } \\
\text { Speciment } \\
\text { Akhir }(\mathrm{g})\end{array}$ & 1,79 & 1,81 & 1,80 \\
\hline Heel/Belakang & $\mathrm{C}$ & $\mathrm{D}$ & 1,44 \\
\hline $\begin{array}{c}\text { Berat } \\
\text { Speciment } \\
\text { Awal (g) }\end{array}$ & 1,47 & 1,40 & 1,31 \\
\hline $\begin{array}{c}\text { Berat } \\
\text { Speciment } \\
\text { Akhir }(\mathrm{g})\end{array}$ & 1,33 & 1,29 & 31,07 \\
\hline $\begin{array}{c}\text { Abrasi Front } \\
\left(\mathrm{mm}^{3}\right)\end{array}$ & 25,42 & 36,72 & 35,31 \\
\hline $\begin{array}{c}\text { Abrasi Heel } \\
\left(\mathrm{mm}^{3}\right)\end{array}$ & 39,54 & 31,07 & 33,19 \\
\hline \multicolumn{2}{c|}{ ABRASI RATA-RATA HEEL }
\end{tabular}

Keterangan :

*Jika SG $\geq 0,9$ Maka Abrasive Max 150

*Jika SG $\leq 0,9$ Maka Abrasive Max 250

Perhitungan Abrasi Material Nitrile Butadine Rubber (NBR)

Tabel 7. Hasil Perhitungan Abrasi material NBR (baru)

\begin{tabular}{c|c|c|c}
\hline Font/depan & A & B & $\begin{array}{c}\text { RATA- } \\
\text { RATA }\end{array}$ \\
\hline $\begin{array}{c}\text { Berat } \\
\text { Speciment } \\
\text { Awal (g) }\end{array}$ & 2,38 & 2,16 & 2,27 \\
\hline $\begin{array}{c}\text { Berat } \\
\text { Speciment } \\
\text { Akhir (g) }\end{array}$ & 2,02 & 1,71 & 1,87 \\
\hline Heel/Belakang & $\mathrm{C}$ & $\mathrm{D}$ & \\
\hline
\end{tabular}




\begin{tabular}{c|c|c|c}
\hline $\begin{array}{c}\text { Berat } \\
\text { Speciment } \\
\text { Awal }(\mathrm{g})\end{array}$ & 1,81 & 1,84 & 1,83 \\
\hline $\begin{array}{c}\text { Berat } \\
\text { Speciment } \\
\text { Akhir }(\mathrm{g})\end{array}$ & 1,45 & 1,49 & 1,47 \\
\hline $\begin{array}{c}\text { Abrasi Front } \\
\left(\mathrm{mm}^{3}\right)\end{array}$ & 102,56 & 128,20 & 115,38 \\
\hline $\begin{array}{c}\text { Abrasi Heel } \\
\left(\mathrm{mm}^{3}\right)\end{array}$ & 102,56 & 99,71 & 101,14 \\
\hline \multicolumn{3}{|c|}{ ABRASI RATA-RATA HEEL } & 108,26 \\
\hline
\end{tabular}

Keterangan :

*Jika SG $\geq 0,9$ Maka Abrasive Max

150

*Jika SG $\leq$ 0,9 Maka Abrasive Max

250

Perhitungan Abrasi Material NBR (sudah digunakan)

Tabel 8. Hasil Perhitungan Abrasi material NBR (sudah digunakan)

\begin{tabular}{|c|c|c|c|}
\hline Font/depan & A & B & $\begin{array}{l}\text { RATA- } \\
\text { RATA }\end{array}$ \\
\hline $\begin{array}{c}\text { Berat } \\
\text { Speciment } \\
\text { Awal (g) }\end{array}$ & 2,36 & 2,14 & 2,25 \\
\hline $\begin{array}{c}\text { Berat } \\
\text { Speciment } \\
\text { Akhir }(\mathrm{g})\end{array}$ & 2,01 & 1,70 & 1,85 \\
\hline Heel/Belakang & $C$ & $\mathrm{D}$ & \\
\hline $\begin{array}{c}\text { Berat } \\
\text { Speciment } \\
\text { Awal (g) }\end{array}$ & 1,80 & 1,83 & 1,82 \\
\hline $\begin{array}{c}\text { Berat } \\
\text { Speciment } \\
\text { Akhir (g) }\end{array}$ & 1,45 & 1,49 & 1,47 \\
\hline $\begin{array}{l}\text { Abrasi Front } \\
\left(\mathrm{mm}^{3}\right)\end{array}$ & 101,49 & 127,58 & 114,53 \\
\hline $\begin{array}{l}\text { Abrasi Heel } \\
\left(\mathrm{mm}^{3}\right)\end{array}$ & 101,77 & 98,91 & 100,34 \\
\hline \multicolumn{3}{|c|}{ ABRASI RATA-RATA HEEL } & 107,44 \\
\hline $\begin{array}{l}\text { Keterangan : } \\
\text { *Jika SG } \geq 0,9 \mathrm{M} \\
150 \\
\text { *Jika SG } \leq 0,9 \mathrm{M} \\
250\end{array}$ & Abrasiv & $\begin{array}{l}\text { Max } \\
\text { Max }\end{array}$ & \\
\hline
\end{tabular}

Dari data hasil analisa ketahanan abrasi pada material Outsole Polyurethane (PU) dan Nitrile Butadine Rubber (NBR) diperoleh beberapa kesimpulan dengan tabel 9 di bawah:

Tabel 9. Hasil Perhitungan Abrasi material PU \& NBR

\begin{tabular}{|c|c|c|c|}
\hline \multirow{2}{*}{ Keterangan } & \multicolumn{2}{|c|}{ Baru } & \multirow{2}{*}{$\begin{array}{c}\text { Rata-Rata } \\
\text { Front \& } \\
\text { Heel }\end{array}$} \\
\hline & Front & Heel & \\
\hline PU & $\begin{array}{c}36,41 \\
\mathrm{~mm}^{3}\end{array}$ & $\begin{array}{c}37,81 \\
\mathrm{~mm}^{3} \\
\end{array}$ & $37,11 \mathrm{~mm}^{3}$ \\
\hline Nitrile & $\begin{array}{c}115,38 \\
\mathrm{~mm}^{3}\end{array}$ & $\begin{array}{c}101,14 \\
\mathrm{~mm}^{3} \\
\end{array}$ & $\begin{array}{c}108,26 \\
\mathrm{~mm}^{3}\end{array}$ \\
\hline \multirow[b]{2}{*}{ Keterangan } & \multicolumn{2}{|c|}{ Sudah digunakan } & Rata-Rata \\
\hline & Front & Heel & $\begin{array}{c}\text { Front \& } \\
\text { Heel }\end{array}$ \\
\hline PU & $\begin{array}{l}31,07 \\
\mathrm{~mm}^{3}\end{array}$ & $\begin{array}{c}35,31 \\
\mathrm{~mm}^{3}\end{array}$ & $33,19 \mathrm{~mm}^{3}$ \\
\hline Nitrile & $\begin{array}{c}114,53 \\
\mathrm{~mm}^{3}\end{array}$ & $\begin{array}{l}100,4 \\
\mathrm{~mm}^{3}\end{array}$ & $\begin{array}{c}107,44 \\
\mathrm{~mm}^{3}\end{array}$ \\
\hline
\end{tabular}

Dimana:
$\mathrm{A}=$ Abrasi outsole front $R H$ material Polyurethane (PU) atau Nitrile Butadine Rubber (NBR)
$\mathrm{B}=$ Abrasi outsole front LH material Polyurethane (PU) atau Nitrile Butadine Rubber (NBR)
$\mathrm{C}=$ Abrasi outsole heel $R H$ material Polyurethane (PU) atau Nitrile Butadine Rubber (NBR)
$\mathrm{D}=$ Abrasi outsole heel $R H$ material Polyurethane (PU) atau Nitrile Butadine Rubber (NBR).

Dan hasil perhitungan abrasi ditunjukan pada diagram barang sebagai berikut :

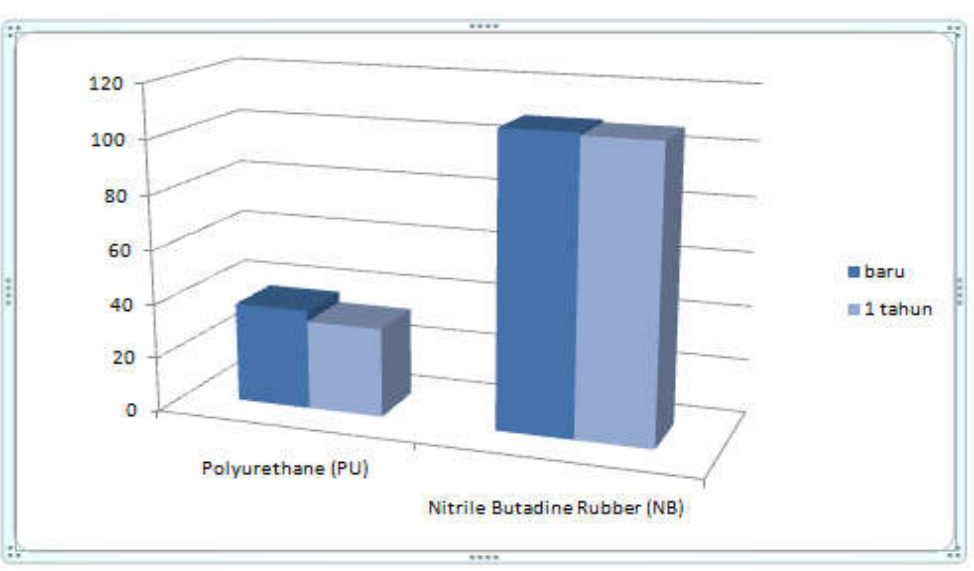

Gambar 2. Diagram Hasil Perhitungan Abrasi Material PU \& NB 


\section{KESIMPULAN}

Dari perhitungan ketahanan abrasi pada material Outsole Polyurethane (PU) dan Nitrile Butadine Rubber (NBR) dapat disimpulkan bahwa :

Outsole dengan material Nitrile Butadine Rubber (NBR) untuk ketahanan abrasi lebih besar yakni 108,26 $\mathrm{mm}^{3}$ untuk yang bersifat baru, dan ketahanan abrasi sebesar 107,44 $\mathrm{mm}^{3}$ untuk Outsole yang sudah digunakan dalam masa 1 tahun dan hanya mengalami penurunan kualitas sebesar 1\%/tahun. dibandingkan outsole dengan material Polyurethane (PU) dengan ketahanan abrasi sebesar $37,11 \mathrm{~mm}^{3}$ dan ketahanan abrasi sebesar 33,19 $\mathrm{mm}^{3}$ untuk Outsole yang sudah digunakan dalam masa 1 tahun dan mengalami penurunan kualitas sampai dengan $11 \%$ / tahun. Sehingga bisa disimpulkan untuk umur pakai safety shoes dengan material Nitrile Butadine Rubber (NBR) bisa bertahan lebih lama dibandingkan safety shoes dengan material Polyurethane (PU).

\section{UCAPAN TERIMA KASIH}

Pada kesempatan ini penulis dengan senang hati menyampaikan terima kasih kepada yang terhormat :

1. Dr. Piatur Pangaribuan, A.Md.,S.H.,M.H.,C.L.A， selaku Rektor Universitas Balikpapan

2. Merry K. Sipahutar,S.Pi.,M.Si.,Ph.D, selaku Ketua Lembaga Penelitian dan Pengabdian Masyarakat (LPPM) Universitas Balikpapan

3. Dr. Ir. M. Isradi Zainal, M.T., M.H., M.M.,CAAE., IPM.,A.Eng, selaku Dekan Fakultas Teknologi Industri Universitas Balikpapan.

4. Direktur dan seluruh jajaran manajemen PT. Forta Larese Indonesia.

5. Berbagai pihak yang telah memberikan bantuan dan dorongan serta berbagi pengalaman pada proses penyusunan penelitian ini.

Penelitian ini kami ajukan dananya kepada Universitas Balikpapan dengan nomor surat tugas (kontrak penelitian): 02/ST/LPPMUNIBA/III/2019.
Penulis menyadari bahwa penelitian ini belum sempurna, baik dari segi materi maupun penyajiannya. Untuk itu saran dan kritik yang membangun sangat diharapkan dalam penelitian ini.

\section{DAFTAR PUSTAKA}

[1] Daniel Tjitra. 2014. Website Forta Larese. Cheetah Safety, Jakarta.

[2] Daniel Tjitra, 2017. Catalog CheetahSafety. Cheetah Safety, Jakarta.

[3] Dewi, Indiah Ratna. 2014. Lateks karet alam untuk sol sepatu : Metode pembuatan, sifat mekanik dan morfologi, Yogyakarta.30(2).6170.

[4] Encyclopaedia,Britannica,2018,https://www.br itannica.com/technology/nitrile-rubber.

[5] Mubaroq, Sony.2014. Analisa Kecacatan pada produksi sepatu nike G40 dengan metode FMEA (Failure mode and effect analysis) dan merancang perawatan mesin Polyurethane ( $P U$ ) sol sepatu di PT.XYZ, Universitas $\mathrm{Al}$ Azhar Indonesia, Jakarta.50(1). 733 - 739.

[6] SNI 0111-2009. Sepatu Pengaman dari kulit dengan sol karet sistem cetak vulkanisasi.

[7] Syahrul Riskan. 2016. Company Profile. QA \& QC. Cheetah Safety,Bogor.

[8] Yuniari,A. 2010. Pengaruh penggunaan Nitrile Butadiene Rubber dan Pale Crepe pada pembuatan sol karet untuk sepatu pengaman. Majalah Kulit,Karet dan plastic, Yogyakarta.26(1). 01-08. 